\title{
Complex Co-Substrate Addition Increases Initial Petroleum Degradation Rates During Land Treatment by Altering Bacterial Community Physiology
}

Christopher W. Kaplan, Brian G. Clement, Alice Hamrick, Robert W. Pease, Carl Flint, Raul J. Cano, and Christopher L. Kitts

A pilot-scale land treatment unit (LTU) was constructed at the former Guadalupe oil production field with the purpose of investigating the effect of co-substrate addition on the bacterial community and the resulting rate and extent of total petroleum hydrocarbon (TPH) degradation. The TPH was a weathered mid-cut distillate (C10-C32) excavated from the subsurface and stockpiled before treatment. A control cell (Cell 1) in the LTU was amended with nitrogen and phosphorus while the experimental cell (Cell 2) was amended with additional complex co-substrate-corn steep liquor. During the pilot LTU operation, measurements were taken of TPH, nutrients, moisture, aerobic heterotrophic bacteria (AHB), and diesel oxidizing bacteria (DOB). The bacterial community was also assayed using community-level physiology profiles (CLPP) and 165 rDNA terminal restriction fragment (TRF) analysis. TPH degradation in both cells was characterized by a rapid phase of degradation that lasted for the first three weeks, followed by a slower degradation phase that continued through the remainder of the project. The initial rate of TPH-degradation in Cell $1\left(-0.021\right.$ day $\left.^{-1}\right)$ was slower than in Cell $2\left(-0.035\right.$ day $\left.^{-1}\right)$. During the slower phase, degradation rates in both cells were similar (-0.0026 and -0.0024 respectively). AHB and $D O B$ counts were similar in both cells during the fast degradation phase. A second addition of co-substrate to Cell 2 at the beginning of the slow degradation phase resulted in an 
increased AHB population that lasted for the remainder of the project but did not affect TPH degradation rates. CLPP data showed that co-substrate addition altered the functional capacity of the bacterial community during both phases of the project. However, TRF data indicated that the phylogenetic composition of the community was not different in the two cells during the fast degradation phase. The bacterial phylogenetic structure in Cell 2 differed from Cell 1 after the second application of co-substrate, during the slow degradation phase. Thus, co-substrate addition appeared to enhance the functional capacity of the bacterial community during the fast degradation phase when the majority of TPH was bioavailable, resulting in increased degradation rates, but did not affect rates during the slow degradation phase when the remaining TPH may not have been bioavailable. These data show that co-substrate addition might prove most useful for applications such as land farming where TPH is regularly applied to the same soil and initial degradation rates are more important to the project goals.

\section{INTRODUCTION}

Bioremediation is the conversion of undesirable compounds (pollutants) into preferable end products using biological processes. This process is well documented for petroleum hydrocarbons (Abed et al., 2002;Admon et al., 2001;Al-Awadhi et al., 1996;Atlas \& Bartha, 1972; Huesemann \& Truex, 1996;

Juck et al., 2000; Mishra et al., 2001; Morgan \& Watkinson, 1990;Venosa et al., 1996); however, chemical, physical, and biological factors can affect the rate and extent of hydrocarbon 
degradation. These factors include specific hydrocarbon compound structures, their bioavailability, and the nature of the soil or matrix in which the petroleum resides. In addition, environmental conditions such as the type and quantity of nutrients, moisture, soil $\mathrm{pH}$, and the availability of suitable electron acceptors are important factors affecting the degradation rate. Despite these caveats, bioremediation is commonly used to remediate petroleum-contaminated soils.

The addition of nutrients, electron acceptors, and moisture has long been advocated to optimize biodegradation capacity, especially in highly engineered systems such as land treatment units (Huesemann \& Truex, 1996; MacNaughton, 1999; Mishra et al., 2001; Morgan \& Watkinson, 1990).The addition of a co-substrate such as methane is commonly used during bioremediation of chlorinated compounds such as trichloroethane (Watanabe, 2001). In contrast, co-substrate addition has not been investigated for the enhancement of petroleum degradation. In part, this is because total petroleum hydrocarbons (TPH) are widely considered to be a readily degradable mixture of compounds. However, petroleum is a very complex mixture, and there are many compounds in TPH that may not be readily degraded. In particular, weathered petroleum may be enriched in poorly degradable components (Admon et al., 2001; Alexander, 2000; Salanitro et al., 1997). Co-substrate additions may therefore be important to the remediation of aged petroleum, where the more readily degradable components are either gone or have already been partially oxidized during weathering.

This study involved the remediation of highly weathered TPH in sandy soil from the former Guadalupe petroleum extraction facility. The Guadalupe site occupies nearly 2,700 acres of the larger Guadalupe-Nipomo Dune Complex and is located on the central California coast in San 
Luis Obispo and Santa Barbara counties. Natural gas and extremely viscous crude oil were extracted at the site from 1946 to March 1994. A refined petroleum product, referred to as diluent, was injected into wells to thin the viscous crude oil and enhance extraction. The diluent, a light petroleum distillate, was similar to a mixture of kerosene and diesel oil. Over the course of 20 to 30 years, diluent was inadvertently released from the network of supply pipes and storage tanks into soil and groundwater at the site.

Biological land treatment was identified as one method for treating the affected soil, and a pilot project including the construction and operation of an on-site land treatment unit (LTU) was commissioned. The pilot project was designed to evaluate the efficacy of bioremediation for diluent-affected soil and the effects of co-substrate supplementation on diluent biodegradation. As part of the pilot project, the authors also sought to determine the effects of co-substrate addition on bacterial community physiology and phylogenetic structure.

\section{MATERIALS AND METHODS}

Site Description

The pilot LTU was constructed approximately two miles east of the Pacific Ocean. The climate is characterized as Mediterranean with an average annual precipitation of $32 \mathrm{~cm}$ and a mean temperature of $13^{\circ} \mathrm{C}$. Chemicals of concern identified in soils treated in the pilot study were limited to TPH in the diluent range (C10-C32). Baseline sampling results showed the soil did not contain polynuclear aromatic hydrocarbons (PAHs); benzene, toluene, ethylbenzene, and xylenes (BTEX); or polychlorinated bi-phenyls (PCBs). The diluent-affected soil treated during the pilot study was the result of past excavation projects. Prior to treatment, the affected soil contained average total petroleum hydrocarbon (TPH) concentrations of approximately 2,000 mg/kg. 
This study involved the remediation of highly weathered TPH in sandy soil from the former Guadalupe petroleum extraction facility.

\section{Cell Construction}

After screening with a one-inch mesh to remove aggregate material, affected soil was transported from existing stockpiles to the treatment area. Approximately 12,000 cubic yards of material was divided between the cells in four 18-inch layers called "lifts.” The lowest lift was not amended but the top three lifts were amended with nutrients to enhance biodegradation. The top lift was designated as the treatment lift. The soil in each cell extended to an approximate total height of 60 inches above the compacted subgrade. The treatment cells were separated by a 15-foot-wide access road and concrete k-rails.

\section{Tilling Depth and Frequency}

Tilling was performed to distribute nutrients and moisture throughout the cells and was generally performed whenever water or other amendments were added.The tilling process created an 18-inchdeep windrow perpendicular to the prevailing wind.Tilling both cells required approximately one day. Due to problems in maintaining tilling depth there was a period of time in the middle of LTU operations when the soil in the top lift was mixed with soil from the lift below.

\section{Nutrient and Co-Substrate Application}

Nutrients in the form of ammonium sulfate and monopotassium phosphate or ammonium phosphate were first dissolved in water and then applied using a water truck to Lifts 1 through 3 
during construction of the cells. The rate of application was calculated to obtain the optimal C:N:P ratios of 100:6:1 as established in previous bench-scale studies. Nutrients were reapplied to the cells when analyses showed that the levels were below the desired C:N:P ratio. Corn steep (CPC International, Westchester, IL), a byproduct of high-fructose corn syrup production, was added to the top lift of Cell 2 as a co-substrate to test the effects on TPH degradation. Prior to its application, the corn steep was diluted with water to reduce its viscosity and enhance even application. The corn steep was administered in two doses of 0.2 percent by weight.

\section{Water Application}

Bench-scale studies determined that the optimum soil moisture content was between 50 and 70 percent of the soil's water holding capacity or from 8 to 10 percent water by weight. Water was heavily applied to each of the cells during construction because the initial soil moisture content was very low. Laboratory analysis and visual inspection were used to determine the water application rates. The initial application was approximately 6 percent water by weight. Later doses were decreased to 3 percent, then less than 2 percent by weight to maintain optimum conditions. At the start of the pilot study, the cells were watered once a week. The frequency of water application was increased during hotter weather; however, the volume of water applied to each cell did not increase. Instead, it was added in two applications in an effort to maintain a constant moisture level throughout the week.The soil moisture content (percent by weight) of each sample was measured using EPA Method 160.3 (Zymax Laboratories, San Luis Obispo, CA).

Tilling was performed to distribute nutrients and moisture throughout the cells and was

\section{Sampling}


A sample grid of ten squares was established for each cell. When sampling a grid square, ten grab samples were obtained from approximately 9 inches into the treatment lift and were then combined in a stainless steel bowl. The composite soil sample was collected in four- or eightounce sample jars for shipping to the analysis laboratories. During LTU operations, the soil was sampled weekly through December 1998 and then once in January and once in February of 1999. Five out of the ten sample grid squares were sampled in each cell during one sampling event and the other five were sampled in the next sampling event. All samples collected were submitted for microbial, TPH , and moisture analyses. Nutrient and soil $\mathrm{pH}$ analyses were conducted weekly through Day 35. Following Day 35 of operations, the frequency of these analyses was decreased to every other week.

\section{Oxygen Monitoring}

The oxygen concentration within the cell soil was measured using Pogo-Probe Oxygen Sensors (Microbac Laboratories, Wexford, PA). Oxygen data was recorded from the area in which samples were obtained. Oxygen measurements were collected after tilling; after rain events; after carbon substrate, water, or nutrient addition; and when the soil had not been tilled for a period of time to determine how these parameters affected soil oxygen concentrations.

\section{Organic and Inorganic Monitoring}

TPH content (mg/kg), carbon chain distribution were measured using method ASTM 2887 and polar fraction was measured using EPA method 418.1 (Zymax Laboratories, San Luis Obispo, CA). Initially, all samples were analyzed for BTEX and PAH (EPA Methods 8260 and 8270). However, these compounds were consistently not detected in the soil, and analyses were discontinued after Day 28 of the study. Zymax Laboratories also monitored soil pH and nutrient 
(ammonia, nitrate, nitrite, sulfate, and ortho-phosphate) levels using the relevant EPA methods (9045, 350.3, or 300.0).

\section{Microbial Monitoring}

Aerobic heterotrophic bacterial counts were estimated by plating four replicate samples for each time point on R2A agar (Difco, Detroit, MI) using the large plate streak method (Jett et al., 1997) after dilution with Bushnell-Hass medium (Difco). Plates were incubated at $28^{\circ} \mathrm{C}$ for three weeks before counting colony-forming unit (CFU). Diesel-oxidizing bacteria were estimated by the MPN method on 96-well microplates (Wrenn \& Venosa, 1996). CommunityLevel Physiological Profiles (CLPP) were produced using Biolog GN plates (Biolog, Hayward, CA). After 100-fold dilution in Bushnell-Hass medium, each sample was distributed into four Biolog GN plates. The plates were scored after 1 week of incubation by reading the absorbance at $560 \mathrm{~nm}$ in a 96-well spectrophotometer (Beckman-Coulter, Fullerton, CA).The phylogenetic structure of the bacterial community was estimated using 16S rDNA terminal restriction fragment analysis. The five samples from each sampling event were combined, and DNA was extracted from the composite sample using the MoBio Soil DNA kit (Solana Beach, CA). PCR was performed using conditions and primers previously described (Kaplan et al., 2001). PCR products were digested with the restriction endonuclease DpnII and DNA fragments were analyzed on an ABI310 genetic analyzer (Applied Biosystems Inc., Foster City, CA). Agglomerative hierarchical cluster analysis of the CLPP and TRF data was performed with Minitab (Minitab Inc., State College, PA) statistical software using Euclidean distances and average cluster linkages.

Five out of the ten sample grid squares were sampled in each cell during one sampling 
event and the other five were sampled in the next sampling event.

\section{RESULTS}

Moisture, Temperature, $\mathrm{pH}$, and Oxygen

The average moisture content in Cell 1 over the entire operation time was 6.5 percent with a low of 3.4 percent on Day 49 and a high of 10.2 percent on Day 91.The average moisture content in Cell 2 was also 6.5 percent with a low of 5.5 percent on Day 169 and a high of 8.3 percent on Day 63 (Exhibit 1). During operation of the LTU, the ambient air temperature decreased from a 24-hr average of $62^{\circ} \mathrm{F}$ in September to $53^{\circ} \mathrm{F}$ in December. The soil temperature averaged $76^{\circ} \mathrm{F}$ during the month of September and $74^{\circ} \mathrm{F}$ in October, and dropped to an average $64^{\circ} \mathrm{F}$ and $54^{\circ} \mathrm{F}$ in November and December, respectively (data not shown).The $\mathrm{pH}$ in the Cell 1 soil was initially measured at 7.0. It increased to a maximum of 7.5 on Day 28, and then declined to average 6.9 until Day 169 when it dropped to a low of 6.3.The pH in the Cell 2 soil was initially measured at 7.4. It increased to a maximum of 8.2 on Day 7, and then declined to average 7.0 from Day 14 until Day 167. For the duration of the pilot study, under all conditions tested, the treatment lift (Lift 1) was aerobic in both cells. Oxygen concentrations within Lift 1 of both cells remained between 15 and 19 percent at 12 to 18 inches into a windrow peak. Aerobic conditions were present even when the treatment lift had not been tilled for a week (data not shown).

Nutrients

Ammonium concentrations were initially low in both cells and increased significantly after a second application of ammonium sulfate (Exhibit 2). Concentrations remained low initially in 
Cell 1 requiring a third application of ammonium sulfate. Ammonium concentrations decreased throughout the rest of the study in both cells with a slight increase after the first rain of the season in November. On Day 110, an application of ammonium phosphate was added to Cell 1. Nitrite appeared in both cells after Day 28 as the initial peak in ammonia began to decrease. Nitrite remained low ( $<25 \mathrm{mg} / \mathrm{kg}$ ) and then disappeared in both cells after the 12th week of operations. Nitrate appeared in both cells immediately after the appearance of nitrite. Nitrate levels remained around $30 \mathrm{mg} / \mathrm{kg}$ after the 8th week of operation in both cells. Phosphate remained between 10 and $20 \mathrm{mg} / \mathrm{kg}$ in both cells throughout the study. Sulfate was higher in Cell 1 (80 to $120 \mathrm{mg} / \mathrm{kg}$ ) than Cell 2 (40 to $80 \mathrm{mg} / \mathrm{kg}$ ), probably because of the additional application of ammonium sulfate to Cell 1 (data not shown).

Ammonium concentrations were initially low in both cells and increased significantly after a second application of ammonium sulfate.

[Insert Exhibit 1]

[Insert Exhibit 2]

[Insert Exhibit 3]

[Insert Exhibit 4]

TPH Reduction and Changes in Carbon-Chain Distribution

By Day 28 in Cell 1, the initial TPH concentration (2,440 mg/kg) decreased by 42 percent; by the end of the project 61 percent of the TPH was removed. TPH loss was greater in Cell 2 at a 
90 percent confidence interval. By Day 28 in Cell 2, the initial TPH concentration (1,760 $\mathrm{mg} / \mathrm{kg}$ ) decreased by 50 percent; by the end of the project 64 percent of the TPH was removed (Exhibit 3). Initially, the light-end hydrocarbon fraction (C12-C20) of TPH was 60 percent in Cell 1 and 56 percent in Cell 2. By day 28 the C12-C20 fraction had decreased in both cells, to 40 percent in Cell 1 and 46 percent in Cell 2.As a result the long-chain hydrocarbons became the dominant fraction in both cells by Day 28. Intriguingly, the C12-C20 fraction increased in both cells by the end of the study, to 55 percent in Cell 1 and 53 percent in Cell 2.This may reflect the accumulation of partial degradation products from longer chain hydrocarbons after Day 28. Throughout the study the C20-C24 fraction was the largest.The average polar fraction in both cells varied between 15 percent and 25 percent during the study; although Cell 1 initially had a higher polar fraction than Cell 2, 34 percent and 20 percent, respectively.

The degradation of TPH in both cells had two distinct phases-an initial fast degradation phase, followed by a slow degradation phase. To determine the breakpoint in the degradation rates, regression analysis was performed on a dataset broken into two groups (early and late). Sample membership within the early and late groups was varied so that all possible breakpoints were considered. The breakpoint that best fit the data in both cells put Days 0 to 21 in the early group and Days 28 to 168 in the late group, indicating that the change in degradation rate occurred between sampling Days 21 and 28 (Exhibit 4).The initial rate constant (k1) for Cell 2 was 50 percent larger than for Cell 1 and was significantly different (p $=0.1$ ) at a 90 percent confidence level. In addition, rate constants for the C12-C14 and C14C16 carbon-chain fractions were significantly higher in Cell 2 at a 95 percent confidence level (Exhibit 5). Conversely, the two cells had very similar second-stage rate constants (k2) for all 
carbon-chain fractions. Although degradation rates were higher for short-chain hydrocarbons (C12-C20) during the fast degradation phase, the long-chain hydrocarbons (C20-C32) had higher degradation rates during the slow degradation phase. The polar fraction was rapidly reduced in Cell 1 during the first two weeks, but remained essentially constant for the remainder of the study. The polar fraction in Cell 2 showed no change throughout the study (data not shown).

[Insert Exhibit 5]

\section{Bacterial Counts}

Aerobic heterotrophic bacterial (AHB) counts were estimated by plating quadruplicate samples onto R2A media. AHB counts for both cells began around $10^{7}$ colony-forming units (CFU) per gram of soil on Day 0 and varied between $10^{7}$ and $10^{9} \mathrm{CFU} / \mathrm{g}$ throughout the study (Exhibit 6). Cell 1 and Cell 2 showed an initial increase in AHB during the first three weeks of operation with doubling times (T2) of 14 and 12 days, respectively. This was followed by a period of decline in AHB that corresponded to the breakpoint between the two degradation rates observed during the study. AHB in Cell 1 began to increase again after Day 28 and continued to grow with a T2 of 99 days, ending at $\sim 10^{8} \mathrm{CFU/g}$ (Exhibit 6A).At Day 50, Cell 2 was amended with a second dose of corn steep in an attempt to reinvigorate the bacterial community and increase TPH degradation. Consequently, AHB counts increased rapidly again for the next three weeks with a T2 of 12 days. After Day 70, AHB counts in Cell 2 remained high $(-5 \times 108)$ for the rest of the study (Exhibit 6B). 
[Insert Exhibit 6]

Diesel oxidizing bacteria (DOB) were estimated in quadruplicate samples using a most probable number (MPN) method. DOB was counted during the first five weeks of the pilot study, covering the period of most active TPH degradation. DOB in both cells varied little, remaining around $-10^{5} \mathrm{MPN} / \mathrm{g}$ soil throughout this period. DOB numbers did not appear to respond to carbon input in Cell 2 and did not reflect the initial increases seen in AHB counts (data not shown).

\section{Community-Level Physiological Profiles (CLPP)}

The physiological profile of the microbial community was monitored as the ability to oxidize the carbon compounds in Biolog GN plates over a 24-hour period (Bending et al., 2002; Kerkhof et al., 2000; Mayr et al., 1999).The CLPP data were averaged across quadruplicate samples, analyzed by cluster analysis and fell into four large clusters that had —60 percent similarity (Exhibit 7). Day 0 samples from both cells grouped together in Cluster 1 with — 85 percent similarity. Samples taken during the fast degradation phase for Cell 1 grouped together in Clusters 1 and 2 with — 58 percent similarity. Samples taken during the fast degradation phase for Cell 2 grouped separately from Cell 1 in Cluster 4 with — 85 percent similarity. Cell 1 samples from Day 77 until Day 126 grouped together in Cluster 3 with — 90 percent similarity. Cell 2 samples from Day 77 until Day 105 grouped together in Cluster 4 with —85 percent similarity. Cell 2 samples from Day 126 grouped with late Cell 1 samples in Cluster 3 with — 80 percent similarity. Samples taken after the end of the fast degradation phase in Cell 1, Days 28 to 70, did not cluster well and had large variations between replicates. In contrast, Cell 2 samples during this same period grouped together in Cluster 4 with the exception of Days 42 and 70. 


\section{$16 S$ rDNA Terminal Restriction Fragment (TRF) Patterns}

The phylogenetic composition of the bacterial community was monitored in both cells by collecting 16S rDNA TRF patterns. The number of TRFs in a pattern is a measure of the number of different bacterial phylotypes present in the sample (Braker et al., 2001; Clement et al., 1998; Kaplan et al., 2001; Kitts, 2001; Liu et al., 1997; Marsh, 1999; Moeseneder, 2001; Sakano et al., 2002).The number of TRFs in both cells increased during the first part of the project. However, while Cell 1 samples retained a high number of TRFs ( -65 ) for the remainder of the study, the number of TRFs in Cell 2 declined after Day 56 to a low of — 45 (Exhibit 8). Cluster analysis of TRF patterns from both cells grouped samples into three large clusters that had — 55 percent similarity (Exhibit 9).The first cluster contained samples from the early part of the study, Cell 1, Days 0 to 42 ( -60 percent similarity) and Cell 2, Days 7 to 28 ( -70 percent similarity). Cell 1 samples from the remainder of the study grouped in Cluster 2 with -60 percent similarity. Cell 2 samples from the later part of the study grouped together in Cluster 3 with -65 percent similarity. In contrast to CLPP data, Day 0 for Cells 1 and 2 did not cluster together. Cell 1, Day 168 grouped with Cell 2, Day 168 in Cluster 2 (—58 percent similarity).

The physiological profile of the microbial community was monitored as the ability to oxidize the carbon compounds in Biology GN plates over a 24-hour period.

[Insert Exhibit 7]

\section{DISCUSSION}


TPH degradation in both pilot LTU cells followed a two-phase kinetic pattern, a commonly reported phenomenon in petroleum bioremediation (Admon et al., 2001; Alexander, 2000; Salanitro et al., 1997).The breakpoint in degradation kinetics occurred between Days 21 and 28 in both cells and was therefore unaffected by co-substrate addition (Exhibit 4). In addition, changes in environmental factors, such as the ambient temperature, $\mathrm{pH}$, and moisture were not correlated with the breakpoint in degradation kinetics (Exhibit 1). Due to the addition of ammonium sulfate the previous week, ammonium levels peaked on Day 21 in both cells (Exhibit 2); however, this addition most likely did not affect degradation rates since a rebound in rates was not observed as ammonium levels decreased after Day 28. Similarly, although the nitrite was detected in both cells from Days 28 to 84, degradation rates did not rebound after nitrite disappeared.

\section{[Insert Exhibit 8]}

Petroleum sequestration in soil particles, which renders it unavailable to bacteria, is the most likely explanation for the observed change in degradation rate. The rate of degradation during the slow phase would thus be limited by the desorption rate of petroleum from soil particles rather than bacterial activity (Admon et al., 2001; Alexander, 2000). Changes in the number or type of bacteria present should not be critical if this is the case. Admon et al. (2001) were able to show a similar effect on initial degradation rates with changes in ambient temperature. As observed here, Admon et al. also saw little or no change in the slow-phase degradation rates. Current techniques for quantifying TPH are carried out using solvents that extract sequestered petroleum, which might be biologically unavailable. To account for the difference in sequestered versus available petroleum it has been suggested that a complementary method of 
analysis should be developed that does not extract sequestered petroleum (Alexander, 2000). The development of such a method would allow for correlation of changes in degradation rates with petroleum bioavailability.

During the fast degradation phase, Cell 2 recorded the highest rate of TPH degradation, especially for the low molecular weight hydrocarbons (Exhibit 5). However, in spite of the addition of the readily utilizable co-substrate corn steep, the doubling time for AHB in Cell 2 was not significantly different from Cell 1 during the first three weeks of LTU operation (Exhibit 6).The DOB count was also similar in both cells during the fast degradation phase. With the exception of Day 0, the phylogenetic structure in both cells was also at least 60 percent similar during this time, implying that the same phylotypes of bacteria were dominant in both cells. Although the initial addition of co-substrate did not significantly alter bacterial numbers or community phylogenetic structure, the CLPP data did show differences between the cells during the fast degradation phase. This implies that corn steep addition resulted in changes to bacterial community physiology that enhanced TPH biodegradation rates, even though the substrates used in the CLPP assay are not necessarily found in TPH so the exact nature of the physiological change induced by corn steep and its relationship to TPH degradation are not clear.

[Insert Exhibit 9]

In addition to increased degradation rates, a higher percentage of the initial TPH was degraded in Cell 2 during this three-week period; 50 percent in Cell 2 versus 42 percent in Cell 1. Perhaps the corn steep, which is composed of protein, lipids, and carbohydrates in an acidic solution, also acted as an emulsifier and increased the initial proportion of bioavailable TPH in Cell 2.

A drop in AHB counts in both cells marked the change in degradation kinetics between 
Days 21 and 28 (Exhibit 6). This is consistent with the idea that the majority of the bioavailable TPH had been utilized at this time. Counts fell abruptly in Cell 1 and more slowly over a threeweek period in Cell 2. Although the change of degradation kinetics appeared abrupt, a transition period of three to four weeks occurred in the bacterial phylogenetic structure of both cells and a similar transition in the CLPP data was also visible in Cell 1 during this time. This gradual transition implies that the change in TPH degradation rate did not result from changes in bacterial abundance or physiology; rather, the bacterial community was adjusting to a more abrupt change in substrate availability mediated by TPH sequestration.

Toward the end of the transition period, Cell 2 received an additional co-substrate amendment that had both short- and long-term effects. For three weeks, the AHB counts in Cell 2 returned to the 12-day doubling time seen at the start of operations, a clear contrast to the 99day doubling time seen in Cell 1 (Exhibit 6). However, the increased bacterial growth did not correlate with an increased TPH degradation rate, suggesting an absence of bioavailable TPH. This implies that the addition of co-substrate on Day 49 did not increase the amount of bioavailable TPH beyond what might have already been emulsified in the first application. Simultaneously, the bacterial phylogenetic structure in the two cells diverged, suggesting that the growth of a group of cosubstrate-specific bacteria was responsible for the increased AHB counts (Exhibit 9). By the end of the project, both the physiological and phylogenetic profiles in the two cells began to converge, suggesting that the effect of co-substrate addition was diminishing (Exhibits 7 and 9).

During the slow degradation phase, the bacterial communities in the two cells were the most dissimilar. During this phase, Cell 1 samples had lower AHB counts, different bacterial phylogenetic structures (Exhibit 9), and different physiological profiles (Exhibit 7) from Cell 2 
samples. However, TPH-degradation rates in the two cells were similar, suggesting that bacterial degradation potential was not determining degradation kinetics during this phase. This is consistent with the hypothesis that TPH was sequestered in the soil, leaving it biologically unavailable, and that the TPH desorption rate was driving the overall degradation kinetics.

\section{CONCLUSIONS}

The addition of complex co-substrates to petroleum land treatment operations appears to be effective when added at project initiation. In the early phase of operations when bacterial abundance and physiology are important, the amendment was able to increase TPH-degradation rates by altering bacterial community physiology. It is also possible that corn steep served as an emulsifier, increasing the amount of bioavailable TPH during the fast degradation phase. As a result, a higher percentage of TPH was removed over the same period compared to the control cell. An incidental benefit of corn steep was that only one nutrient addition was necessary to maintain $\mathrm{N}$ and $\mathrm{P}$ levels during the fast degradation phase. However, in the later phase of operations when TPH bioavailability may have been rate-limiting, additional co-substrate was ineffective, even though it clearly altered the abundance and physiology of the bacterial community. Thus, co-substrate addition, while providing limited benefit for soil remediation where the ultimate goal is a clean soil, might prove most useful for applications such as land farming where TPH or sludge is regularly added to the same soil, making the soil a medium for degradation. Since the object of this kind of land farming is the removal of large amounts of TPH and not complete remediation of the soil, an increased initial degradation rate is desirable because it would result in less TPH sequestered in soil particles after each application and result in better degradation efficiency over several sludge applications. 
The addition of complex co-substrates to petroleum land treatment operations appears to be effective when added at project initiation.

\section{ACKNOWLEDGMENTS}

This work was supported by the generous contributions of the UNOCAL Corporation whom we thank for the opportunity to conduct research at their site and for the support of their staff in accomplishing the common goal of a cleaner environment. We also thank everyone at the Environmental Biotechnology Institute, past and present, who contributed to successful completion of the LTU project.

\section{REFERENCES}

Abed, R. M. M., Safi, N. M. D., Köster, J., de Beer, K., El- Nahhal, Y., Rullkötter, J., et al. (2002). Microbial diversity of a heavily polluted microbial mat and its community changes following degradation of petroleum compounds. Applied Environmental Microbiology, 68, 1674-1683.

Admon, S., Green, M., \& Avnimelech, Y. (2001). Biodegradation kinetics of hydrocarbons in soil during land treatment of oily sludge. Bioremediation Journal, 5, 193-209.

Al-Awadhi, N., Al-Daher, R., ElNavavy, A., \& Balba, M. T. (1996). Bioremediation of oilcontaminated soil in Kuwait: Landfarming to remediate oil-contaminated soil. Journal of Soil Contamination, 5, 243-260.

Alexander, M. (2000). Aging, bioavailability, and overestimation of risk from environmental pollutants. Environmental Science and Technology, 34, 4259-4265. 
Atlas, R. M., \& Bartha, R. (1972). Degradation and mineralization of petroleum by two bacteria isolated from coastal wasters. Biotechnology Bioengineering, 14, 297-308.

Bending, G. D., Turner, M. K., \& Jones, J. E. (2002). Interactions between crop residue and soil organic matter quality and the functional diversity of soil microbial communities. Soil Biology and Biochemistry, 34, 1073-1082.

Braker, G., Ayala-del-Rio, H. L., Devol, A. H., Fesefeldt, A., \& Tiedje, J. M. (2001).

Community structure of denitrifiers, bacteria, and archaea along redox gradients in Pacific

Northwest marine sediments by terminal restriction fragment length polymorphism analysis

of amplified nitrite reductase (nirS) and 16S rRNA genes. Applied and Environmental Microbiology, 67, 1893-1901.

Clement, B. G., Kehl, L. E., DeBord, K. L., \& Kitts, C. L. (1998). Terminal restriction fragment patterns (TRFPs), a rapid, PCR-based method for the comparison of complex bacterial communities. Journal of Microbiological Methods, 31, 135-142.

Huesemann, M. H., \& Truex, M. J. (1996). The role of oxygen diffusion in passive bioremediation of petroleum contaminated soils. Journal of Hazardous Materials, 51, 93-113.

Jett, B. D., Hatter, K. L., Huycke, M. M., \& Gilmore, M. S. (1997). Simplified agar plate method for quantifying viable bacteria. Biotechniques, 23, 648-650.

Juck, D., Charles, T., Whyte, L. G., \& Greer, C. W. (2000). Polyphasic microbial community analysis of petroleum hydrocarbon-contaminated soils from two northern Canadian communities. FEMS Microbiology Ecology, 33, 241-249.

Kaplan, C. W., Astaire, J. C., Sanders, M. E., Reddy, B. S., \& Kitts, C. L. (2001). 16S ribosomal 
DNA terminal restriction fragment pattern analysis of bacterial communities in feces of rats fed Lactobacillus acidophilus NCFM. Applied and Environmental Microbiology, 67, 19351939.

Kerkhof, L., Santoro, M., \& Garland. J. (2000). Response of soybean rhizosphere communities to human hygiene water addition as determined by community level physiological profiling (CLPP) and terminal restriction fragment length polymorphism (TRFLP) analysis. FEMS Microbiology Letters, 184, 95-101.

Kitts, C. L. (2001). Terminal restriction fragment patterns: A tool for comparing microbial communities and assessing community dynamics. Current Issues in Intestinal Microbiology, 2, 17-25.

Liu, W., Marsh, T. L., Cheng, H., \& Forney, L. (1997). Characterization of microbial diversity by determining terminal restriction fragment length polymorphisms of genes encoding $16 \mathrm{~S}$ rRNA. Applied and Environmental Microbiology, 63, 4516-4522.

MacNaughton, S. J., Stephen, J. R., Venosa, A. D., Davis, G. A., Chang, Y., \& White, D. C. (1999). Microbial population changes during bioremeditaion of an experimental oil spill. Applied and Environmental Microbiology, 65, 3566-3574.

Marsh, T. L. (1999). Terminal restriction fragment length polymorphism (T-RFLP): An emerging method for characterizing diversity among homologous populations of amplification products. Current Opinion in Microbiology, 2, 323-327.

Mayr, C., Winding, A., \& Hendriksen, N. B. (1999). Community level physiological profile of soil bacteria unaffected by extraction method. Journal of Microbiological Methods, 36, 29-33.

Mishra, S., Jyot, J., Kuhad, R. C., \& Lal, B. (2001). Evaluation of inoculum addition to 
stimulate in situ bioremediation of oily-sludge-contaminated soil. Applied and Environmental Microbiology, 67, 1675-1681.

Moeseneder, M. M., Winter, C., Arrieta, J. M., \& Herndl, G. J. (2001). Terminal-restriction fragment length polymorphism (T-RFLP) screening of a marine archaeal clone library to determine the different phylotypes. Journal of Microbiological Methods, 44, 159-172.

Morgan, P., \& Watkinson, R. J. (1990). Assessment of the potential for in situ biotreatment of hydrocarbon-contaminated soils. Water Sci. Technol, 22, 63-68.

Sakano, Y., Pickering, K. D., Strom, P. F., \& Kerkhof, L. J. (2002). Spatial distribution of total, ammonia-oxidizing, and denitrifying bacteria in biological wastewater treatment reactors for bioregenerative life support. Applied and Environmental Microbiology, 68, 2285-2293.

Salanitro, J. P., Dorn, P. B., Huesemann, M. H., Moore, K. O., Rhodes, I. A., Rice, L. M., et al. (1997). Crude oil hydrocarbon bioremediation and soil ecotoxicity assessment. Environmental Science and Technology, 31, 1769-1776.

Venosa, A. D., Suidan, M. T., Wrenn, B. A., Strohmeier, K. L., Haines, J. R., Eberhart, B. L., et al. (1996).

Bioremediation of an experimental oil spill on the shoreline of Delaware Bay. Environmental Science and Technology, 30, 1764-1775.

Watanabe, K. (2001). Microorganisms relevant to bioremediation. Current Opinions in Biotechnology, 12, 237-241.

Wrenn, B. A., \& Venosa, A. D. (1996). Selective enumeration of aromatic and aliphatic 
hydrocarbon degrading bacteria by a most-probable-number procedure. Canadian Journal of Microbiology, 42, 252-258.

Christopher W. Kaplan was a master's student with the Environmental Biotechnology Institute (EBI) at California Polytechnic State University, San Luis Obispo, California. He is currently a graduate student at the University of California, Los Angeles in the molecular biology program.

Brian G. Clement was an undergraduate with the EBI at California Polytechnic State University, San Luis Obispo, California. He is currently a graduate student at Scripps in San Diego studying manganese oxidizing bacteria with the marine biology research division.

Alice Hamrick was an undergraduate with the EBI at California Polytechnic State University, San Luis Obispo, California. She is currently the laboratory manager and lead technician at the EBI where she runs experiments and coordinates the microbiology and molecular biology projects in the laboratory.

Robert W. Pease is currently a senior project scientist with BFJ Services, Inc. in Santa Maria, California. He manages sampling and data collection for the bioremediation and phytoremediation projects for Unocal Corporation at the Guadalupe Dunes. 
Carl Flint is a chemical engineer with Ablestik Inc. in Rancho Dominguez, California. He managed the land treatment pilot unit study at Guadalupe when he was employed by Unocal Corporation.

Raul J. Cano is a professor with the biological sciences department and the director of the EBI at California Polytechnic State University, San Luis Obispo, California. His current work focuses on diversity analysis of actinobacteria.

Christopher L. Kitts is an associate professor with the biological sciences department and the associate director of the EBI at California Polytechnic State University, San Luis Obispo, California. His research covers the microbial ecology of petroleum bioremediation, tracking bacterial spores in milk powder, probiotic bacteria and the intestinal microbial community, and tracking environmental E. coli contamination. 


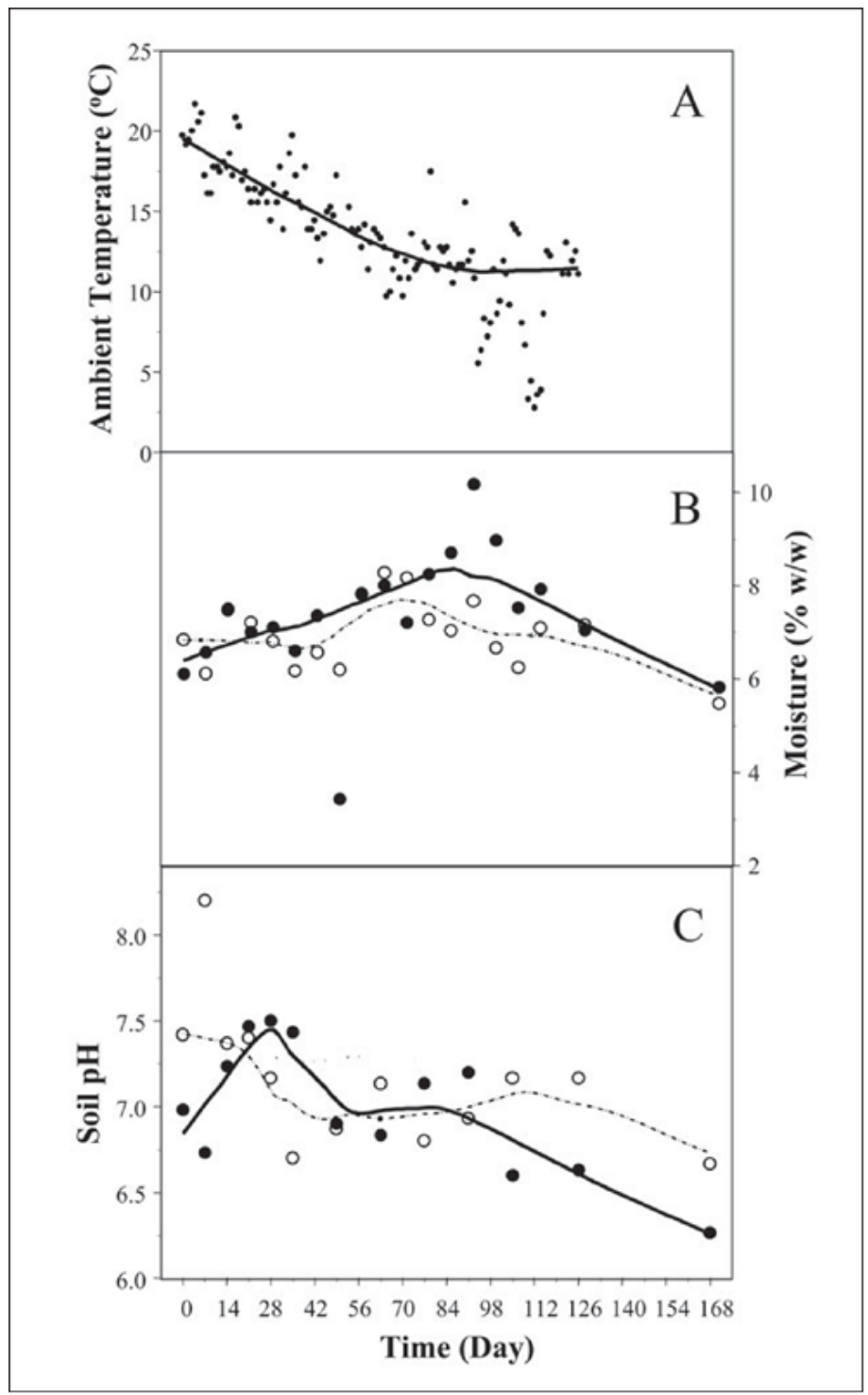

Exhibit 1. Environmental data at the Guadalupe LTU: A) ambient temperature, B) soil moisture, C) soil pH. Cell 1-solid circles and solid lines. Cell 2-open circles and dashed lines 


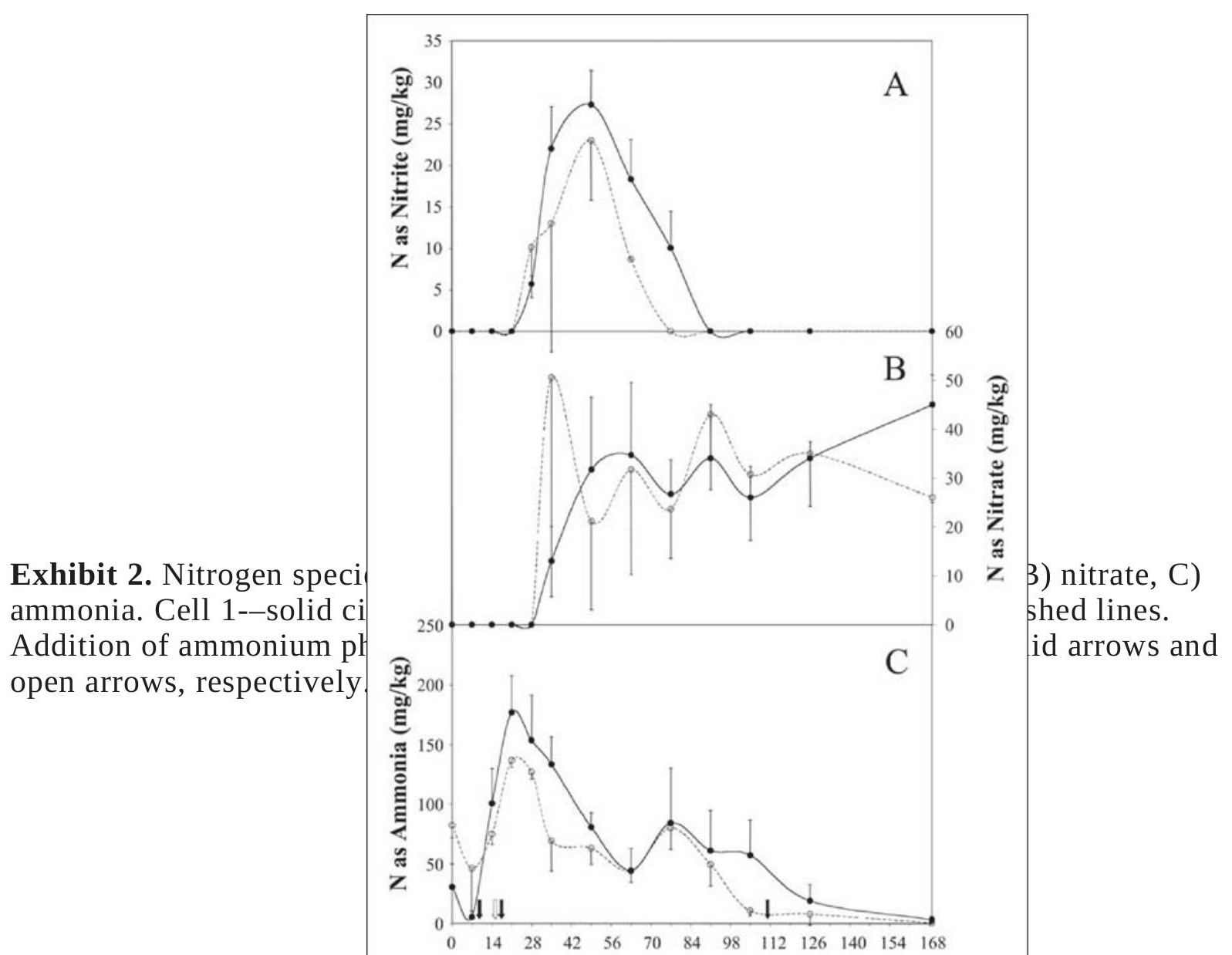




\begin{tabular}{lllllll}
\hline & \multicolumn{2}{l}{$\begin{array}{l}\text { TPH Composition } \\
\text { at day 0 } \\
\text { Cell 1 }\end{array}$} & $\begin{array}{l}\text { Cell 2 } \\
\text { at day 28 }\end{array}$ & $\begin{array}{l}\text { Cell 1 } \\
\text { Cell 2 }\end{array}$ & $\begin{array}{l}\text { TPH Composition } \\
\text { at study end }\end{array}$ & Cell 2 \\
TPH (mg/kg) & $2,440(462)$ & $1,760(134)$ & $1,420(192)$ & $880(72)$ & $960(30)$ & $640(47)$ \\
C12-14 & $5 \%(0.6)$ & $4 \%(0.8)$ & $1 \%(0.1)$ & $1 \%(0.1)$ & $2 \%(0.2)$ & $1 \%(0.2)$ \\
C14-16 & $15 \%(0.7)$ & $14 \%(0.6)$ & $7 \%(0.6)$ & $8 \%(0.4)$ & $12 \%(1.2)$ & $10 \%(1.8)$ \\
C16-18 & $20 \%(0.5)$ & $19 \%(0.3)$ & $14 \%(0.7)$ & $16 \%(0.7)$ & $20 \%(0.6)$ & $20 \%(0.4)$ \\
C18-20 & $20 \%(0.4)$ & $19 \%(0.5)$ & $19 \%(0.5)$ & $21 \%(0.5)$ & $21 \%(0.5)$ & $22 \%(1.3)$ \\
C20-24 & $25 \%(0.5)$ & $26 \%(0.7)$ & $32 \%(0.3)$ & $31 \%(0.2)$ & $28 \%(1.4)$ & $29 \%(1.7)$ \\
C24-28 & $11 \%(0.8)$ & $13 \%(0.3)$ & $19 \%(0.9)$ & $17 \%(0.7)$ & $13 \%(1.0)$ & $14 \%(0.6)$ \\
C28-32 & $4 \%(0.2)$ & $5 \%(0.3)$ & $8 \%(0.9)$ & $6 \%(0.7)$ & $4 \%(0.2)$ & $4 \%(0.4)$ \\
\hline
\end{tabular}

Exhibit 3. Composition of TPH during degradation. The average of five measurements is presented with standard deviations in parentheses 


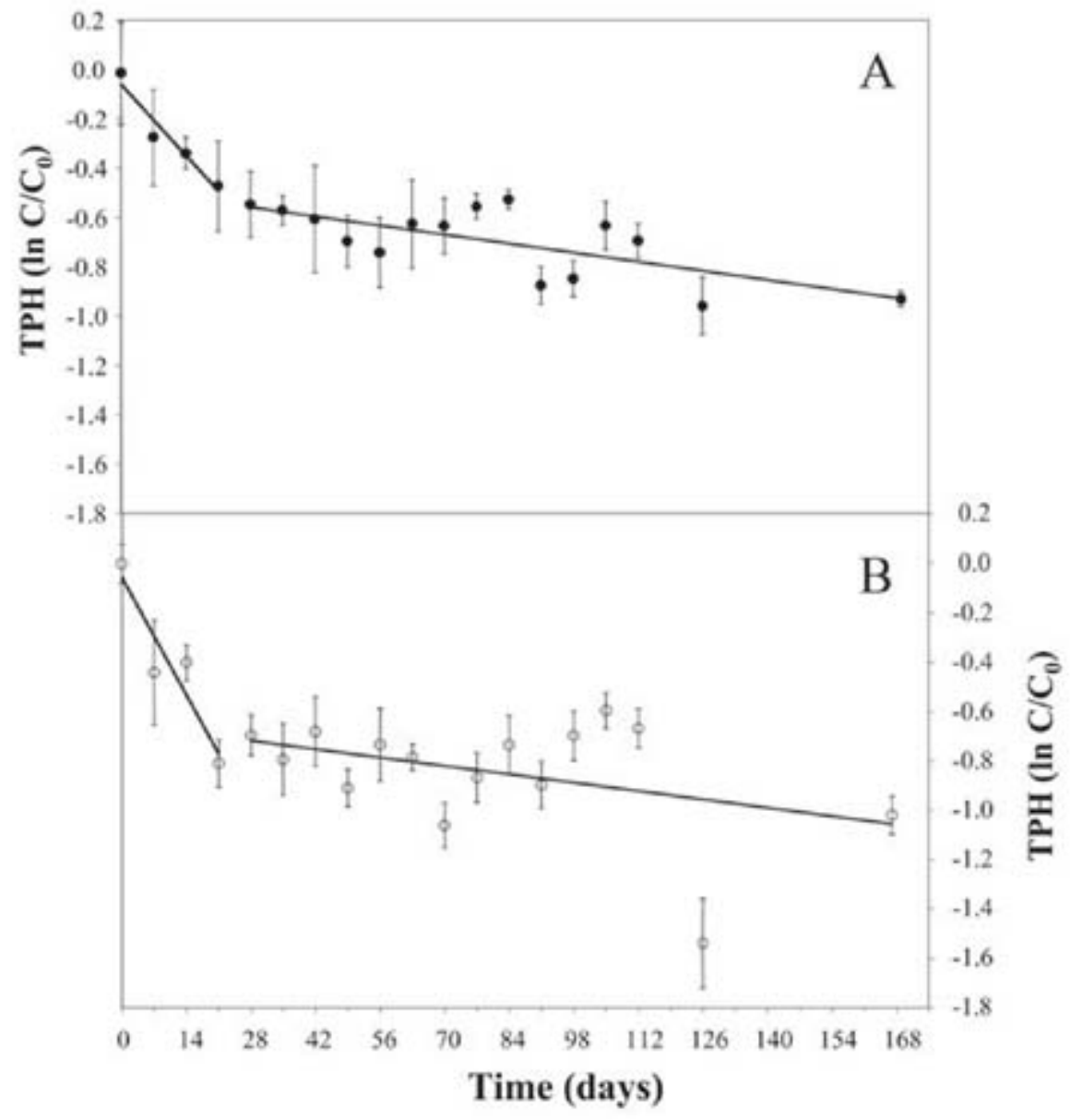

Exhibit 4. Average relative TPH concentration for A) Cell 1-solid circles and B) Cell 2-open circles. Error bars indicate one standard deviation.

\begin{tabular}{lllll}
\hline & \multicolumn{2}{c}{$k_{1}$ (Day 0-21) } & \multicolumn{2}{l}{$k_{2}$ (Day 28-end) } \\
& Cell 1 & Cell 2 & Cell 1 & Cell 2 \\
TPH & -0.021 & $-0.034^{* *}$ & -0.0026 & -0.0024 \\
C12-14 & -0.027 & $-0.116^{*}$ & 0.0001 & 0.0000 \\
C14-16 & -0.023 & $-0.060^{*}$ & -0.0012 & -0.0019 \\
C16-18 & -0.025 & -0.039 & -0.0015 & -0.0017 \\
C18-20 & -0.023 & -0.030 & -0.0020 & -0.0020 \\
C20-24 & -0.019 & -0.025 & -0.0029 & -0.0026 \\
C24-28 & -0.008 & -0.023 & -0.0042 & -0.0036 \\
C28-32 & -0.008 & -0.021 & -0.0064 & -0.0039 \\
- different from rate constant for Cell 1; p $<0.05$ & & \\
*. different from rate constant for Cell 1; p $=0.1$ & & \\
\end{tabular}

Exhibit 5. First-order dimensionless rate constants for hydrocarbon degradation 


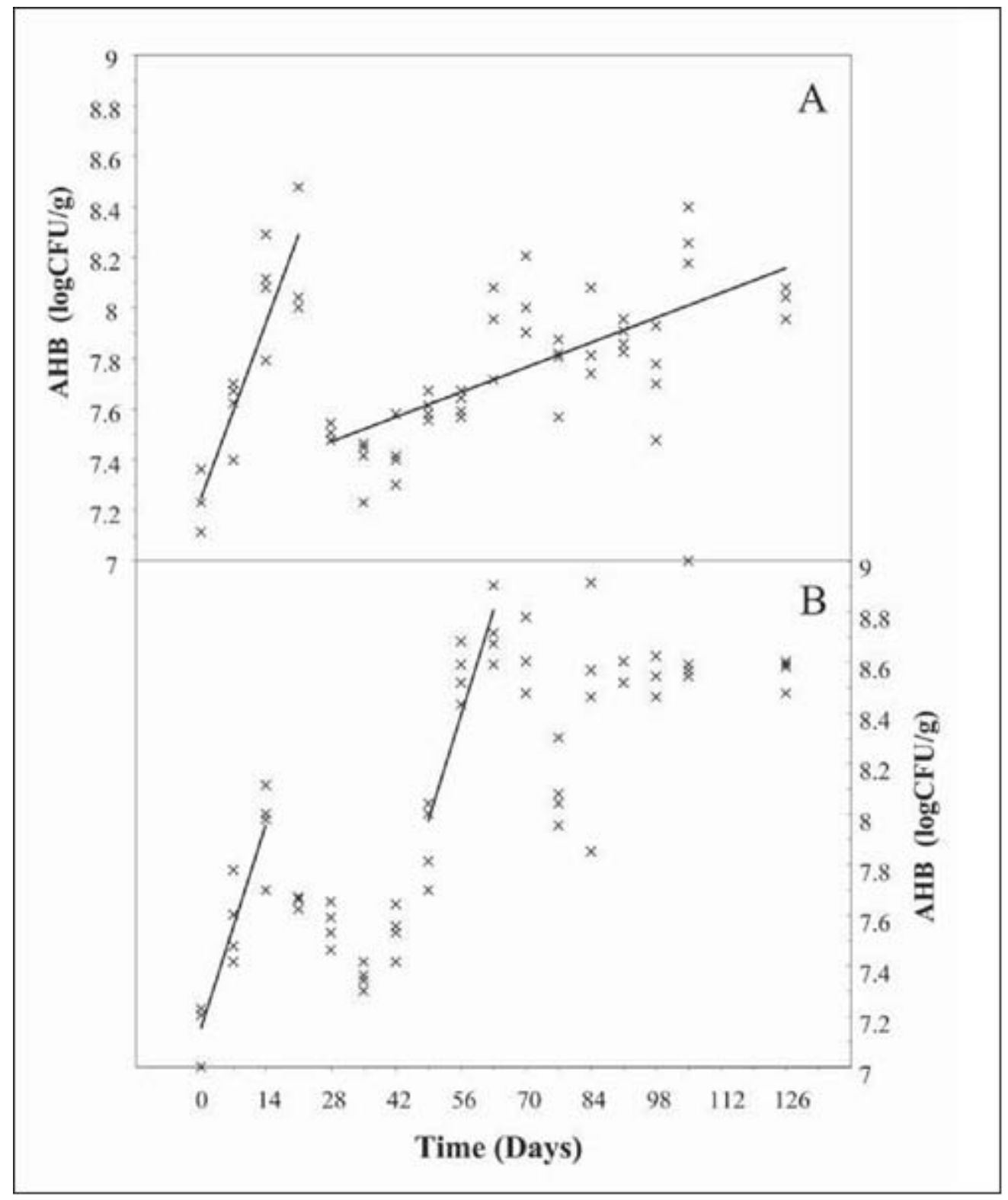

Exhibit 6. Aerobic Heterotrophic Bacterial (AHB) counts for A) Cell 1 and B) Cell 2. Lines indicate regions used to calculate doubling times 


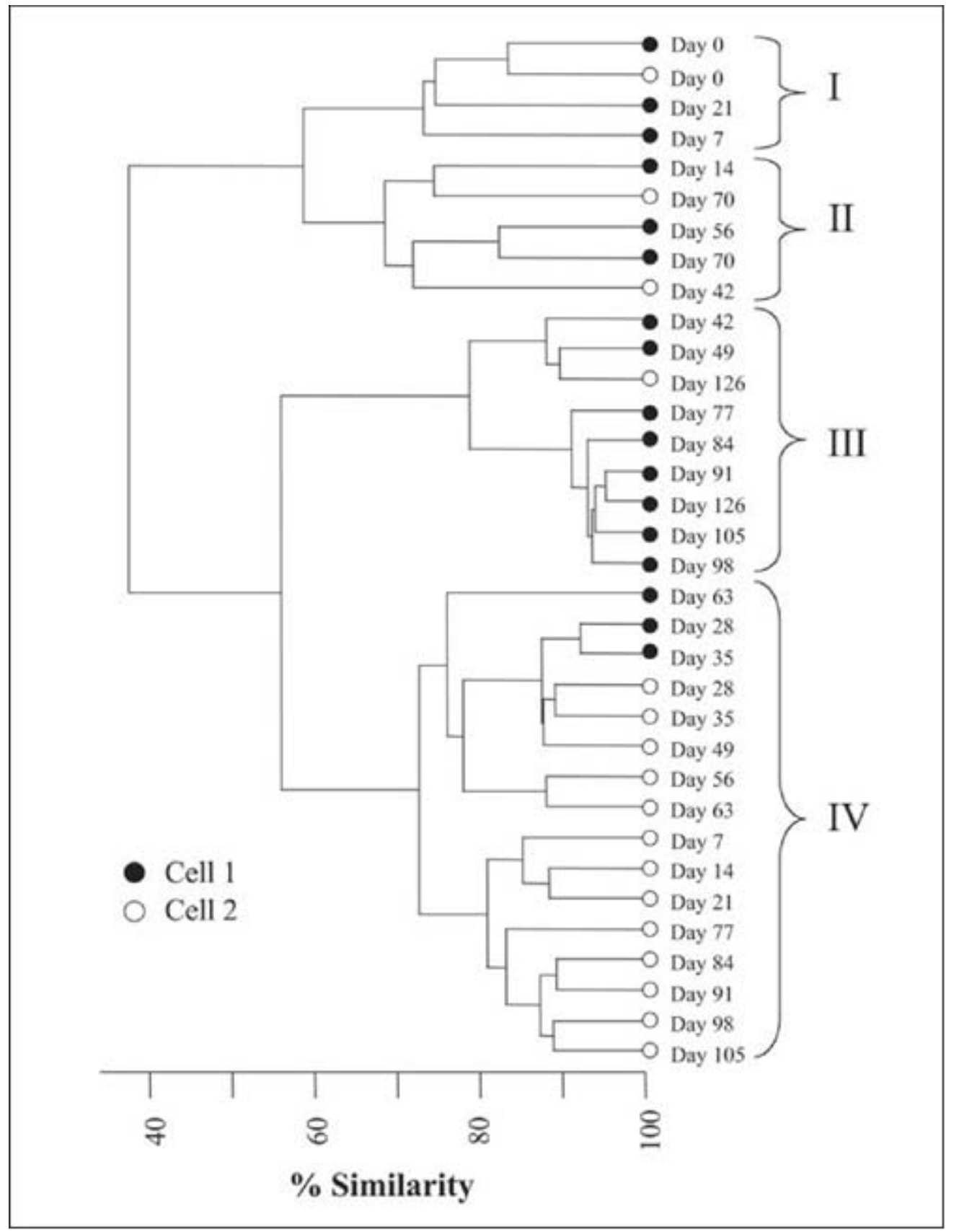

Exhibit 7. Dendogram from agglomerative hierarchical cluster analysis of average communitylevel physiological profiles (CLPP). Cell 1 samples-closed circles; Cell 2 samples-open circles 


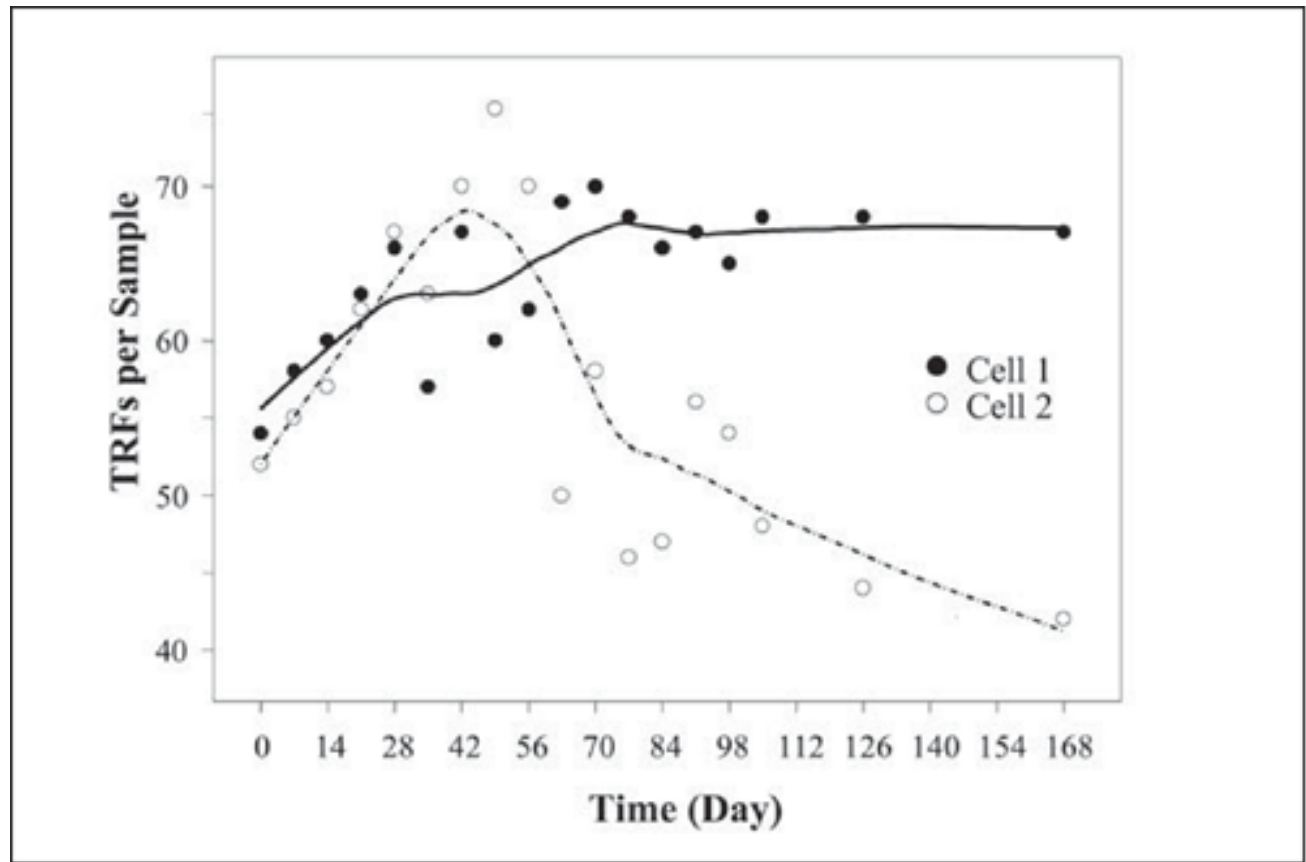

Exhibit 8. Number of bacterial phylotypes (TRFs) present in TRF patterns from LTU samples. Cell 1 samples-closed circles; Cell 2 samples-open circles 


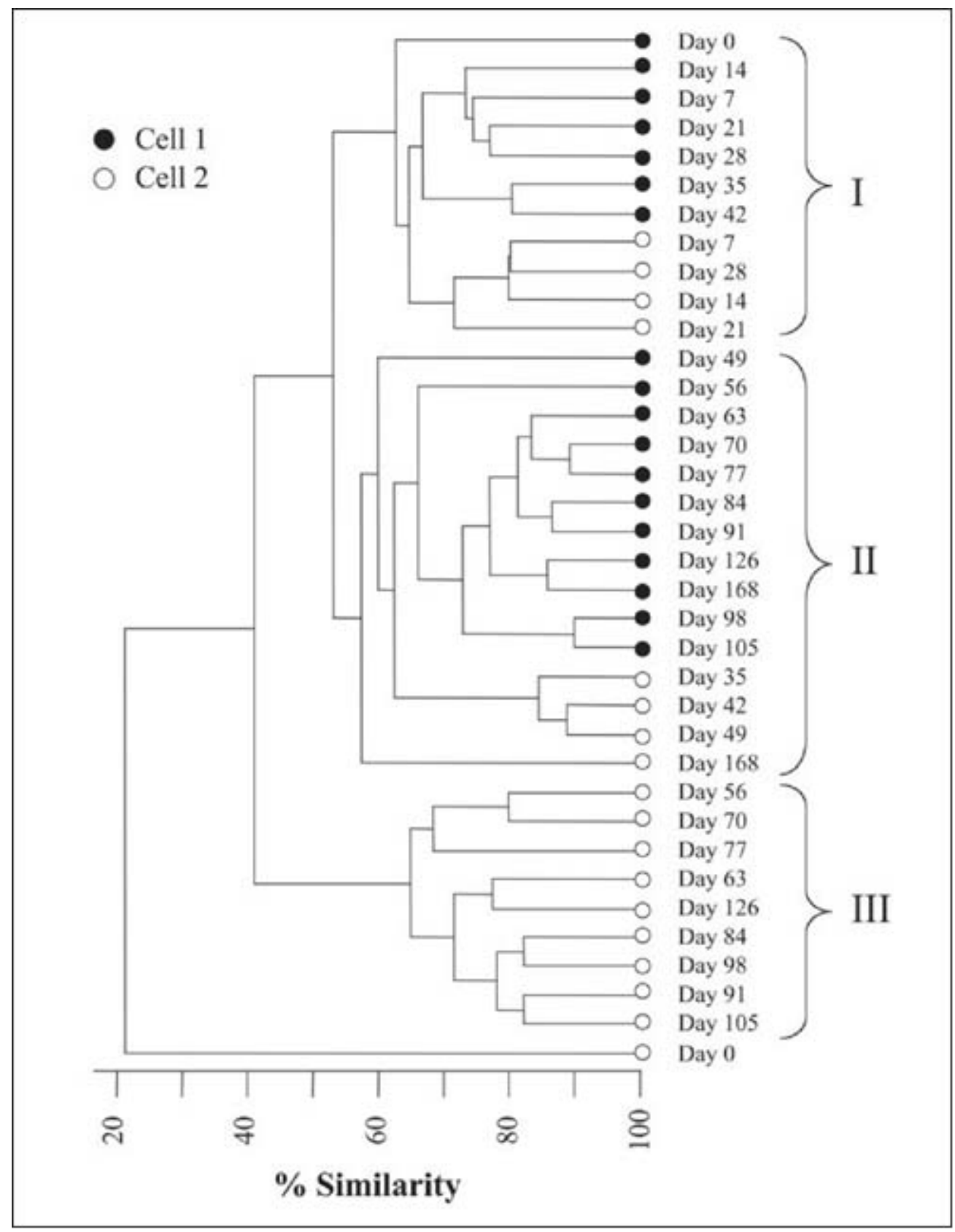

Exhibit 9. Dendogram from agglomerative hierarchical cluster analysis of 16S rDNA TRF patterns. Cell 1 samples-closed circles; Cell 2 samples-open circles 